Revista Brasileira de Agricultura Irrigada v.7, nº. 6, p. 330 - 339, 2013

ISSN 1982-7679 (On-line)

Fortaleza, CE, INOVAGRI - http://www.inovagri.org.br

DOI: $10.7127 /$ rbai.v7n600176

Protocolo 176.13 - 20/08/2013 Aprovado em 22/11/2013

\title{
ZONEAMENTO AGROCLIMÁTICO E AMBIENTAL DA CULTURA DO CAJU PARA O ESTADO DE PERNAMBUCO
}

Sabrina Gomes de Souza ${ }^{1}$; Euvaldo Pereira de Cerqueira Junior ${ }^{2}$; André Quintão de Almeida ${ }^{3}$; Carlos Tiago Amâncio Rodrigues ${ }^{4}$

\section{RESUMO}

O zoneamento agroclimático é uma importante ferramenta utilizada no planejamento agrícola e ambiental de uma determinada região. Porém, na maioria dos casos, as Áreas de Preservação Permanente são desconsideradas nestes estudos. O trabalho teve como objetivo realizar o zoneamento agroclimático e ambiental para espécie do caju (Anacardium occidentale L.) no Estado de Pernambuco, levando em consideração as Áreas de Preservação Permanente. O trabalho foi dividido em duas etapas: (i), elaboração do zoneamento agroclimático do cajueiro; e (ii), elaboração do zoneamento ambiental, com base nas Áreas de Preservação Permanente, conforme a Lei 4.771 do código florestal brasileiro. O zoneamento agroclimático foi realizado a partir das exigências climáticas e topográfica da cultura. Foram utilizados dados normais (>20 anos) de precipitação pluvial, temperatura do ar e deficiência hídrica do solo. No zoneamento ambiental, foram consideradas quatro classes de preservação permanente: (1) ao redor de nascentes, (2) cursos d'água, (3) declividade do terreno maior que $45^{\circ}$ e (4) topo de morro. Na delimitação das classes de preservação permanente, foram utilizadas informações de altitude, extraídas do Shuttle Radar Topography Mission, e a rede hidrográfica de todo o Estado pernambucano. Apenas 3,28\% da área do Estado são agroclimaticamente aptas para o cultivo do cajueiro. Ao se considerar o zoneamento ambiental, foi observada uma redução de $5 \%$ das áreas ótima, regular e restrita para o cultivo da cultura do caju. Em estudos de zoneamento e aptidão agroclimática, devem ser consideradas as Áreas de Preservação Permanente contidas no código florestal brasileiro.

Palavras-chave: aptidão agroclimática, geomática, sensoriamento remoto, APPs.

\section{AGROCLIMATIC AND ENVIRONMENTAL ZONING OF THE CASHEW CROP FOR THE STATE OF PERNAMBUCO}

\footnotetext{
ABSTRACT

${ }^{1}$ Acadêmico de Agronomia, Universidade Federal Rural de Pernambuco -Unidade Acadêmica de Serra Talhada, Fazenda Saco, s/n, caixa postal 603, CEP 56906-410, Serra Talhada - PE. Fone: (87) - 3929-3001. e-mail: sabrinagomes_e.a@hotmail.com.

${ }^{2}$ Acadêmico de Agronomia, Universidade Federal Rural de Pernambuco -Unidade Acadêmica de Serra Talhada, Fazenda Saco, s/n, caixa postal 603, CEP 56906-410, Serra Talhada - PE. e-mail: juniabare@gmail.com

${ }_{3}^{3}$ Engenheiro Florestal, Doutor em Meteorologia Agrícola, Professor Adjunto da Universidade Federal de Sergipe - UFS, Núcleo de Engenharia Agrícola - NEAGRI, Aracaju, SE. tiagoamancio@ hotmail.com

${ }^{4}$ Acadêmico de Agronomia, Universidade Federal Rural de Pernambuco -Unidade Acadêmica de Serra Talhada, Fazenda Saco, s/n, caixa postal 603, CEP 56906-410, Serra Talhada - PE. e-mail: andre.almeida@ufs.br
} 
Agroclimatic zoning is a powerful tool used in agricultural and environment planning of a particular region. However, in most cases Permanent Preservation Areas are disregarded in these studies. The objective of the present study was to perform agroclimatic and environmental zoning for the cashew species (Anacardium occidentale L.) in Pernambuco state, taking into account the Permanent Preservation Areas. The work was divided in two stages: (i) preparation for agroclimatic zoning of the cashew plant, and (ii) preparation for environmental zoning, based on the Permanent Preservation Areas, according to Law 4771 of the Brazilian forest code. Agroclimatic zoning was carried out based on the topographic and climatic requirements of the species. Normal data was used ( $>20$ years) of precipitation, air temperature and soil water deficit. In environmental zoning, four classes of permanent preservation were considered: (1) around springs, (2) streams, (3) hills with slope greater than $45^{\circ}$, and (4) hilltops. In delimiting the classes of permanent preservation, information on elevation was used as extracted from the Shuttle Radar Topography Mission and the hydrographic network of the state of Pernambuco. Only $3.28 \%$ of the area of the state is agroclimatically suitable for the cashew cultivation. When considering environmental zoning, there was a 5\% reduction in the arable area great, regular and restricted for crowing the cashew crop. In studies of agroclimatic zoning and suitability, Permanent Preservation Areas as defined in the Brazilian forest code should be considered.

Keywords: agroclimatic suitibility, geomatics, remote sensing, APPs.

\section{INTRODUÇÃO}

A cultura do caju assumiu papel de destaque na economia da região Nordeste do Brasil, devido à exploração do fruto e do pedúnculo (Aguiar et al., 2003). Esta cultura ocupa a maior parte da mão-de-obra agrícola no período de outubro a dezembro (Aguiar et al., 2001), durante a colheita do fruto. Apesar de amplamente cultivada no Nordeste do país, alguns estados desta região ainda não possuem estudos de zoneamento agrícola para a cultura do caju, identificando as áreas mais adequadas para o cultivo. O passo para a elaboração do zoneamento agrícola de uma grande região envolve a definição dos objetivos, a escala geográfica do estudo e a caracterização das exigências climáticas a serem zoneadas, dentre outros fatores (Pereira et al., 2007).

$\mathrm{Na}$ maioria dos zoneamentos (Aguiar et al., 2001; Aguiar et al., 2003; Garcia et al.,
2010; Rody et al., 2010), são considerados apenas aspectos do clima, solo e relevo, não sendo levados em consideração os aspectos ambientais, como as Áreas de Preservação Permanente (APPs) descritas no código Florestal Brasileiro. O código Florestal, Lei 12.651 de 2012, (Brasil, 2012) dispõe sobre as APPs localizadas nos topos de morros, montes, montanhas, ao redor de nascentes e cursos d'água, sendo vedada a utilização dessas áreas e conseqüente remoção de suas coberturas vegetais originais. As APPs estão protegidas nos termos dos artigos $2^{\circ}$ e $3^{\circ}$ desta Lei, coberta ou não por vegetação nativa, com a função ambiental de preservar os recursos hídricos, a paisagem, a estabilidade geológica, a biodiversidade, o fluxo gênico de fauna e flora e proteção do solo (Conama, 2002). No entanto, no Brasil, estas áreas se encontram com um alto grau de degradação, devido à pressão exercida pelas atividades da agropecuária e o 
crescimento desordenado das áreas urbanizadas (Nascimento et al., 2005; Oliveira et al., 2008; Soares et al., 2011).

Diante do exposto, objetivou-se com este trabalho realizar o zoneamento agrícola e ambiental da cultura do caju (Anacardium occidentale L.) no Estado de Pernambuco, levando em consideração as Áreas de Preservação Permanente.

\section{MATERIAL E MÉTODOS}

O trabalho foi realizado para o Estado de Pernambuco, com área aproximada de 98.148 $\mathrm{km}^{2}$. A unidade da federação está localizada entre as coordenadas $7^{\circ} 20^{\prime}$ a $9^{\circ} 29^{\prime} \mathrm{S}$ e $34^{\circ} 30^{\prime}$ a $41^{\circ} 21^{\prime}$ W e é subdividida em cinco mesorregiões (Figura 1): Metropolitana do Recife, Zona da Mata, Agreste, Sertão e São Francisco. As três primeiras estão sobre a influência do clima As (tropical, com chuvas de outono-inverno) e as duas últimas, sobre a influência do clima BSh (semi-árido).

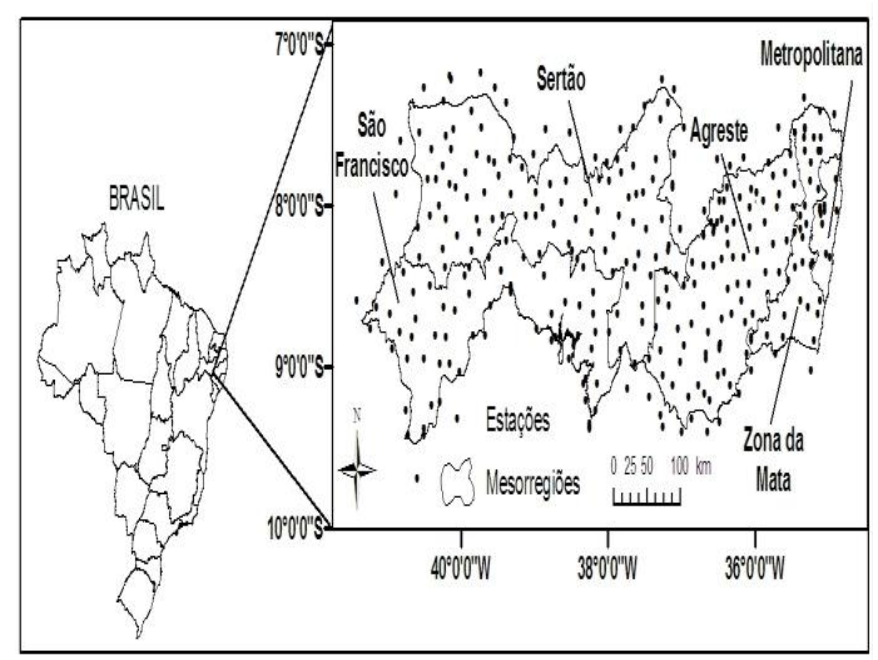

Figura 1. Localização da área de estudo e dos postos pluviométricos.
As exigências agrícolas e topográficas da cultura (Tabela 1) foram extraídas do Ministério da Agricultura, Pecuária e Abastecimento (Mapa, 2011). Na análise, foram avaliadas as quatro classes de aptidão climática e topográfica da cultura, sendo elas: Ótima / baixo risco; Regular / médio risco; Restrita / alto risco; e, Inapta. Foram consideradas as faixas de temperatura média do ar anual $\left({ }^{\circ} \mathrm{C}\right)$, precipitação pluviométrica anual (mm), deficiência hídrica do solo anual $(\mathrm{mm})$ e a altitude $(\mathrm{m})$ em relação ao nível do mar.

Os valores mensais normais de temperatura média do ar foram estimados a partir das equações desenvolvidas por Medeiros et al. (2005). Nestes modelos, as temperaturas médias mensais do ar $\left({ }^{\circ} \mathrm{C}\right)$ são estimadas em função dos valores de longitude $\left({ }^{\circ}\right)$, latitude $\left(^{\circ}\right)$ e altitude $(\mathrm{m})$, e seus respectivos quadrados e produtos cruzados.

Os dados de precipitação foram extraídos de 315 postos pluviométricos (Figura 1). Do total de postos, 254 estão inseridos dentro do contexto do Estado de Pernambuco. Além destes, foram utilizados 61 postos vizinhos ao limite do Estado, auxiliando o processo de interpolação (Cecilio et al., 2012). Apenas 73 postos pluviométricos possuem uma série acima de 30 anos de observações e 181, entre 20 e 30 anos de dados, estando todos compreendidos entre os anos de 1911 e 1990. 
Tabela 1. Classes de aptidão referentes às exigências da cultura do caju.

\begin{tabular}{|c|c|c|c|c|}
\hline \multirow[t]{2}{*}{ Parâmetro } & \multicolumn{4}{|c|}{ Classe } \\
\hline & $\begin{array}{l}\text { Ótima/Baixo } \\
\text { Risco }\end{array}$ & $\begin{array}{c}\text { Regular/Médio } \\
\text { Risco }\end{array}$ & $\begin{array}{l}\text { Restrita/Alto } \\
\text { Risco }\end{array}$ & Inapta \\
\hline $\mathrm{TM}^{1}\left({ }^{\circ} \mathrm{C}\right)$ & $22 \leq \mathrm{TM} \geq 32$ & $32<\mathrm{TM} \leq 40$ & $15 \leq \mathrm{TM}<16$ & $\begin{array}{c}15<\mathrm{TM}> \\
42\end{array}$ \\
\hline $\begin{array}{l}\mathrm{P}^{2}(\mathrm{~mm} \\
\left.\mathrm{ano}^{-1}\right)\end{array}$ & $800<\mathrm{P}<1500$ & $600<\mathrm{P}<800$ & $500<\mathrm{P}<600$ & $\mathrm{P}<500$ \\
\hline $\mathrm{DH}^{3}(\mathrm{~mm})$ & $<350$ & $<350$ & $<350$ & $<350$ \\
\hline $\mathrm{Alt}^{4}(\mathrm{~m})$ & $0<$ Alt $<300$ & $300<$ Alt $<600$ & $600<$ Alt $<900$ & Alt $>900$ \\
\hline
\end{tabular}

1é a temperatura média do ar. é a precipitação pluvial. 3é a deficiência de água no solo. "é a altitude em relação ao nível do mar.

Fonte: Ministério da Agricultura, Pecuária e Abastecimento (2007).

Em cada ponto pluviométrico, foi calculado o balanço hídrico climatológico, com base no método de Thornthwaite e Matter (1955), tendo como variáveis de entrada os dados médios mensais estimados de temperatura do $\operatorname{ar}\left({ }^{\circ} \mathrm{C}\right)$ e a precipitação pluvial mensal $(\mathrm{mm})$. A evapotranspiração potencial foi estimada pelo método de Thornthwaite (1948), que utiliza os dados de temperatura média mensal do ar $\left({ }^{\circ} \mathrm{C}\right)$. Por meio desses cálculos, foram obtidos a evapotranspiração real, a deficiência e o excedente hídrico do solo anual, todos em milímetro. A capacidade máxima adotada de armazenamento de água no solo (CAD) foi a climatológica $(125 \mathrm{~mm})$. Os mapas de precipitação pluviométrica média anual e dos valores de deficiência hídrica anual, foram elaborados pelo método de interpolação do inverso do quadrado da distância, com expoente 2 (Castro et al., 2010).
Os valores de altitude foram extraídos do Modelo Digital de Elevação (MDE) obtido pela Shuttle Radar Topography Mission (Srtm). Com resolução espacial de $90 \mathrm{~m}$ e escala equivalente à 1:250.000 (Sreedevi et al., 2009), estes dados estão disponíveis no site da Agência Espacial Americana (Nasa), no site "http://srtm.usgs.gov/data/obtainingdata.html".

Foram utilizadas na identificação e delimitação das APPs, as informações do relevo e da rede hidrográfica de todo o Estado de Pernambuco. A hidrografia utilizada foi obtida pelo Zoneamento Agroecológico do estado de Pernambuco (Zape), na escala de 1:100.000. As nascentes foram determinadas, considerando o início de cada trecho da rede hidrográfica gerada.

No mapeamento das APPs foi adotada a metodologia de Pelúzio et al. (2010), atendendo rigorosamente as especificações dos art. $2^{\circ}$ e $3^{\circ}$ da Resolução 303/2002 do Conama. As categorias de APPs demarcadas foram as que estavam localizadas ao redor de nascentes (APP-1), cursos d' água (APP-2), nas encostas com declividades superiores a $45^{\circ}$ (APP-3) e no terço superior dos morros (APP-4).

$\mathrm{Na}$ categoria APP-1 foi considerado um raio de $50 \mathrm{~m}$ ao redor das nascentes, tendo-se por origem o ponto associado a cada nascente. Nas APP-2, foi considerado que todos os rios possuíam larguras inferiores a $10 \mathrm{~m}$, sendo que essa categoria foi delimitada estabelecendo-se faixas de 30 metros para ambas as margens. $\mathrm{Na}$ delimitação das APP-3, o MDE foi reclassificado, identificando-se as áreas com declividade superior a $45^{\circ}$. Para demarcar as 
APP-4, foi calculada a relação entre altura do topo do morro em relação à base para cada célula do MDE. Esse procedimento possibilitou identificar todas as células que possuíam relação igual ou superior a dois terços.

Todas as etapas utilizadas no processo de manipulação dos dados: geração dos mapas, cruzamento, análise dos resultados e geração de saídas gráficas, envolveram a utilização de um sistema de informações geográficas, visando à obtenção do mapa final do zoneamento agrícola e ambiental do Estado de Pernambuco para a cultura do cajueiro.

\section{RESULTADOS E DISCUSSÃO}

Na Figura 2, são apresentados os mapas de altitude e dos valores anuais de temperatura do ar, deficiência hídrica do solo e precipitação pluvial.

Os valores de altitude variaram entre zero, ao nível do mar, e aproximadamente 2000 metros, na Messoregião do Agreste. Os valores máximos e mínimos de temperatura média anual do ar variaram entre 19 e $26^{\circ} \mathrm{C}$. Observase uma forte relação inversa entre os valores de temperatura do ar e a altitude, com as menores temperaturas ocorrendo nos locais mais altos do Estado. Este resultado é esperado, uma vez que os valores de temperatura do ar foram estimados a partir de equações de regressão quadrática ajustadas por Cavalcanti et al. (2006), tendo como uma das variáveis independentes os valores de altitude. A deficiência hídrica do solo foi maior nas regiões de clima semiárido, na porção leste, no sertão do Estado. Os maiores valores de deficiência de água no solo estão correlacionados com os baixos valores de precipitação anual encontrados, próximos de $400 \mathrm{~mm}$ ano $^{-1}$. Os mais elevados totais precipitados (> 2000 $\mathrm{mm}$ ) foram encontrados nas regiões Metropolitana e da Zona da Mata.

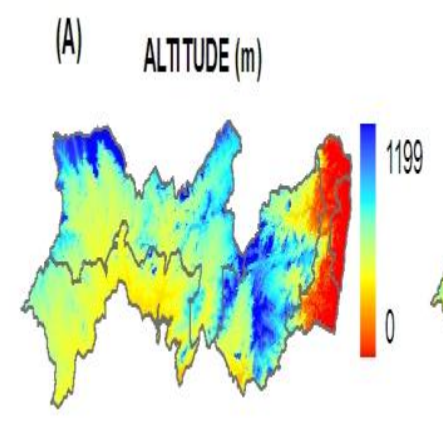

(B) TEIIPERTURA (C)
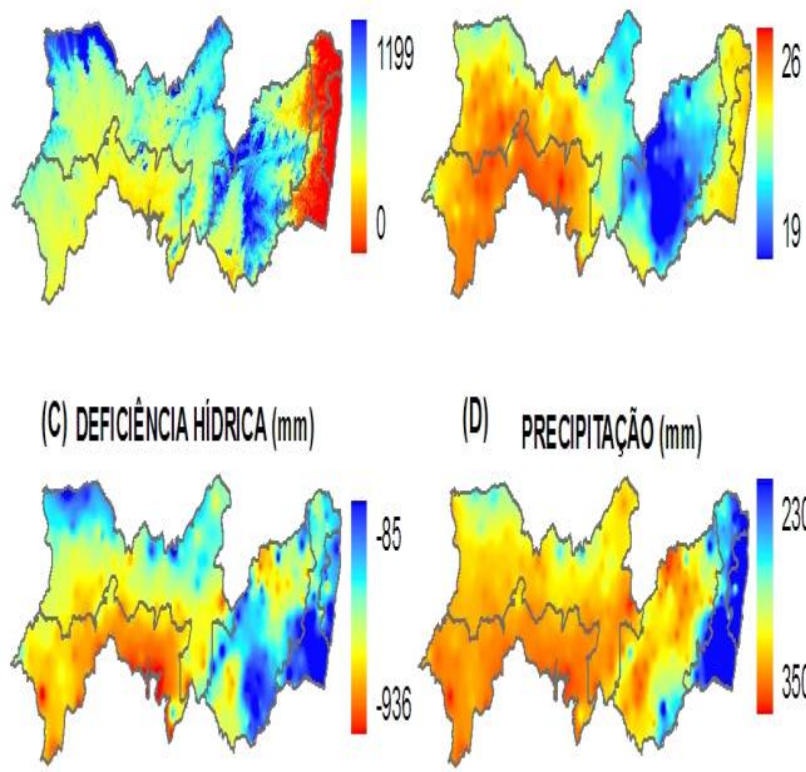

(D) PRECPTRCACO(m)

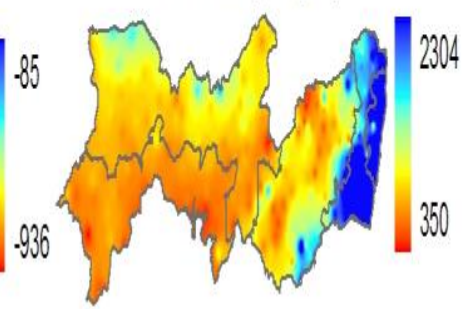

Figura 2. Variabilidade espacial da altitude (A), temperatura do ar (B), deficiência hídrica do solo (C) e precipitação pluvial (D) para o Estado de Pernambuco.

As quatro diferentes classes de aptidão climática, considerando os valores de altitude, temperatura do ar, deficiência hídrica do solo e precipitação pluvial, para a espécie do caju no Estado de Pernambuco, sendo elas, ótima, regular, restrita e inapta, estão apresentadas na Figura 3. 
As classes de aptidão referentes à altitude, indicando como área apta as com os menores valores de altitude, estão concentradas nas mesorregiões da Zona da Mata e Metropolitana (Figura 3A). Nestas regiões, são observados os valores de altitude considerados ótimos para o cultivo da cultura (Tabela 1), com valores de elevação abaixo de 300 metros em relação ao nível do mar. As regiões aptas para a cultura, referentes às exigências de temperatura do ar (Figura 3B), considerando uma faixa térmica de $22{ }^{\circ} \mathrm{C}$ a $32{ }^{\circ} \mathrm{C}$, abrangem todo o Estado. Logo para o cultivo do caju não há restrições quanto a temperatura do ar no Estado de Pernambuco. Com relação à deficiência de água no solo, (Figura 3C), a cultura do caju tolera valores superiores a -350 $\mathrm{mm}$, o que confere a este uma boa capacidade de resiliência. Mesmo apresentando uma boa resiliência o cultivo do cajueiro se torna inviável em sequeiro na maior parte do Estado devido grande parte das regiões possuírem uma deficiência de água no solo muito alta.
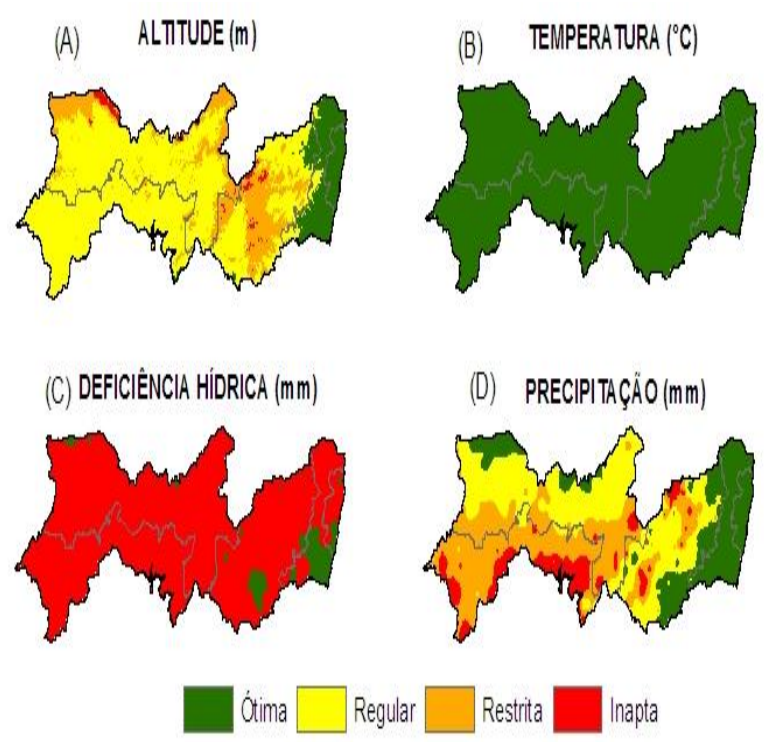

Figura 3. Áreas aptas para o cultivo do caju no Estado de Pernambuco considerando as variáveis agroclimáticas analisadas, altitude (A), temperatura do ar (B), deficiência de água no solo (C) e precipitação (D).
Os índices de precipitações exigidos pela cultura, faixa compreendida entre $800 \mathrm{~mm}$ a $1500 \mathrm{~mm}$, abrange a região da Zona da Mata, região Metropolitana, uma pequena parte do Agreste e do Sertão Pernambucano (chapada do Araripe). Estas regiões apresentam um potencial pluviométrico superior quando comparado às outras regiões do Estado, o que se torna determinante para o cultivo da cultura do caju. Porém, em grande parte do Estado há o predomínio de áreas regulares e com restrição para o cultivo do caju, podendo haver produção, não havendo o máximo desempenho produtivo da cultura, sob condições de sequeiro.

$\mathrm{Na}$ Figura 4 é apresentado o mapa do zoneamento agroclimático do caju para o Estado Pernambucano. As regiões mais indicadas (Ótima) para o cultivo da espécie estão localizadas numa pequena parte do Agreste, Zona da Mata e Região Metropolitana do Recife, compreendendo 3,28\% (3225,9 km²) de todo o estado. Devido à temperatura exigida pela cultura abranger todo o Estado, os fatores determinantes para o zoneamento do caju foram os índices de precipitação, altitude e deficiência hídrica no solo. Como área regular $(1,01 \%)$ obteve-se uma pequena parte do Agreste e da Zona da Mata, sendo esta última situada às redondezas da área considerada ótima do ponto de vista agroclimático. A área restrita, 1902,3 km² (1,93\%), compreende uma pequena parte do Agreste e do Sertão, restringindo-se à Chapada do Araripe. Grande parte do Estado apresenta áreas inaptas para o cultivo do caju, devendo-se principalmente à 
restrição dos índices pluviométricos, altitude e deficiência hídrica exigidos pela cultura, compreendendo uma área de aproximadamente 92185, $6 \mathrm{~km}^{2}$, ou seja, 93,77\% da área total do Estado.

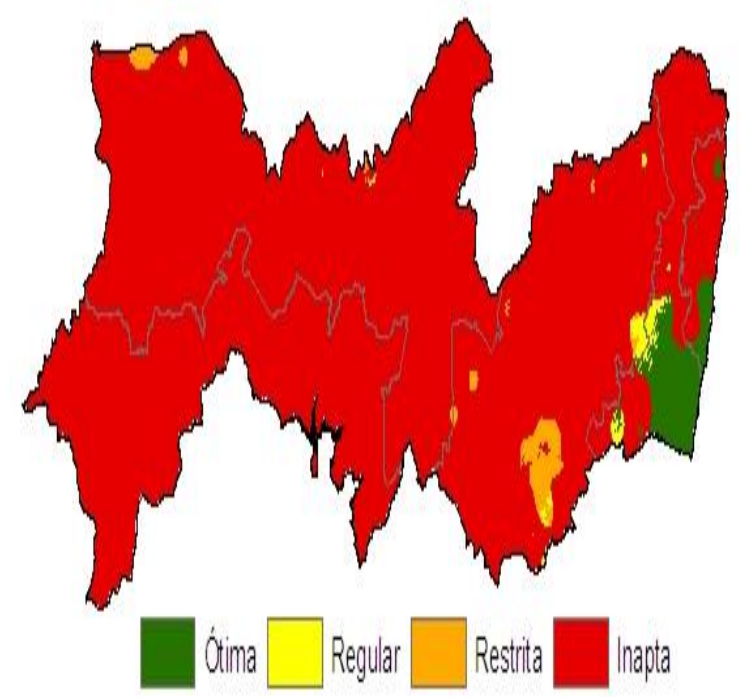

Figura 4. Zoneamento agrícola do caju (Anacardium occidentale L.) para o Estado de Pernambuco.

A Figura 5 apresenta as classes de APPs identificadas no Estado de PE. Na Tabela 2, são apresentadas as áreas $\left(\mathrm{km}^{2}\right)$ e suas respectivas porcentagens de ocorrência de APPs dentro do Estado.

Da área total $\left(98.148 \mathrm{~km}^{2}\right)$ analisada, apenas $15,84 \%$ são legalmente protegidas. Deste total, a classe de APPs com a maior área mapeada foi a de topo de morro, com 13697,1 $\mathrm{km}^{2}$. A classe de preservação permanente com menor área mapeada foi aquela com declividade acima de $45^{\circ}$. Boa parte das classes de preservação mapeada no contexto do Estado de PE está localizada nas Messoregiões do Agreste e da Zona da Mata, locais com presença de relevo mais acidentado (montanhoso).

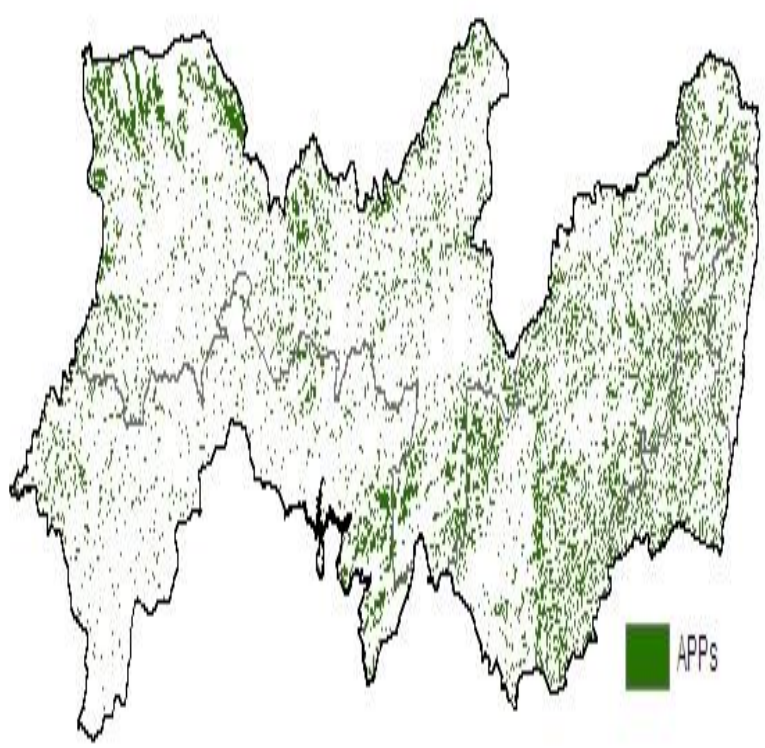

Figura 5. Mapa das classes de áreas de preservação permanentes delimitadas para o Estado de Pernambuco.

Diversos trabalhos de delimitação automática de APPs mostram resultados semelhantes ao encontrado neste trabalho, com as maiores porcentagens de área de preservação localizadas nos topos de morros (Nascimento et al., 2005; Oliveira et al., 2008; Soares et al., 2011). O baixo valor encontrado na classe de APP-3, nas áreas com declividade superior a $45^{\circ}$, pode ser explicado, em partes, pela baixa resolução espacial $(90 \mathrm{~m})$ e pela baixa escala equivalente (1:250.000) do SRTM. Em um estudo de delimitação de APPs, considerando duas diferentes escalas topográficas, 1:10.000 e 1:50.000, Almeida et al. (2007) encontraram uma diferença de $40 \%$ na área total de APPs mapeadas. Em trabalhos futuros, sugere-se, que os valores de altitude e declividade sejam 
extraídos de fontes altimétricas com maior escala.

Tabela 2. Quantificação das áreas de preservação permanente que compõem o Estado de Pernambuco.

\begin{tabular}{lcc} 
APPs & Área $\left(\mathrm{km}^{2}\right)$ & $\%$ \\
\hline 1 - Nascentes & 523,56 & 0,53 \\
2 - Curso d' água & 1346,57 & 1,37 \\
3 - Declividade & 1,35 & 0,00 \\
4 - Topo de morro & 13697,11 & 13,93 \\
\hline Total & 15568,60 & 15,84 \\
\hline
\end{tabular}

A Tabela 3 apresenta o resultado do zoneamento agrícola e ambiental, realizado para a cultura do caju (Anacardium occidentale L.) no Estado de PE. Este resultado foi gerado a partir do cruzamento do zoneamento agrícola e das classes de APP's, onde apresenta as efetivas áreas para o cultivo da cultura em estudo.

Ao analisar em conjunto, o zoneamento agrícola e ambiental, considerando a delimitação de quatro classes de Áreas de Preservação Permanente, pôde-se observar, de um modo geral, uma redução nas áreas aptas para o cultivo do caju. Nota-se uma diferença significativa entre as áreas consideradas como ótima, regular e restrita no zoneamento agrícola e no ambiental, havendo uma queda respectiva de $2,75 \% ; 0,78 \%$ e $1,47 \%$. Conseqüentemente, aumentando em aproximadamente 5,01 \% a classe inapta. Desta forma há uma importante diferença na área que é considerada apta para o cultivo do caju e a área que pode vir a ser agricultável.

Tabela 3. Zoneamento agrícola e ambiental para o caju (Anacardium occidentale L.) para o Estado de Pernambuco.

\begin{tabular}{lcccc} 
& \multicolumn{2}{c}{ Agrícola } & \multicolumn{2}{c}{ Ambiental } \\
\cline { 2 - 5 } & Área $\left(\mathrm{km}^{2}\right)$ & $\%$ & Área $\left(\mathrm{km}^{2}\right)$ & $\%$ \\
\hline \multirow{2}{*}{ Ótima } & 3225,88 & 3,28 & 519,71 & 0,53 \\
Regular & 997,19 & 1,01 & 223,26 & 0,23 \\
Restrita & 1902,28 & 1,93 & 454,37 & 0,46 \\
Inapta & 92185,64 & 93,77 & 97113,65 & 98,78 \\
\hline
\end{tabular}

\section{CONCLUSÕES}

A região Sul da Zona da Mata Pernambucana pode ser considerada climaticamente apta para o cultivo do caju (Anacardium occidentale L.).

O estudo integrado do zoneamento agroclimático e a delimitação das Áreas de Preservação Permanente inseridas no interior do Estado de PE, reduziram em 5\% as áreas ótimas, regular e restrita para a cultura do cajueiro.

\section{REFERÊNCIAS BIBLIOGRÁFICAS}

AGUIAR, M. J. N. et al. Zoneamento pedoclimático para a cultura do cajueiro (Anacardium occidentale L.) na região Nordeste do Brasil e no norte de Minas Gerais. 
Revista Brasileira de Agrometeorologia, Sete Lagoas, v. 9, n. 3, p. 557-563, 2001.

AGUIAR, M. J. N. et al. Zoneamento pedoclimático para a cultura do cajueiro (Anacardium occidentale L.) no estado da Bahia. EMBRAPA: Boletim de Pesquisa e Desenvolvimento. Fortaleza, CE. 32p. 2003.

ALMEIDA, A. Q.; SANTOS, A. R.; PEZZOPANE, J. E. M. Comparação entre áreas de preservação permanente demarcadas a partir de diferentes escalas topográficas. Revista Capixaba de Ciência e Tecnologia, Vitória, v. 2, n. 4, p. 1-8, 2007.

BRASIL. Lei n. 12.651, de 25 de maio de 2012. Institui o novo Código Florestal Brasileiro. Diário Oficial da República Federativa do Brasil, Brasília. Disponível em: <http://www6.senado.gov.br/legislacao/ListaPu blicacoes. action?id=102353>. Acesso em: 20 ago. 2012.

CASTRO, F. S. et al. Avaliação do desempenho dos diferentes métodos de interpoladores para parâmetros do balanço hídrico climatológico. Revista Brasileira de Engenharia Agrícola e Ambiental, Campina Grande, v. 14, n. 8, p. 871-880, 2010.

CAVALCANTI, E. P.; SILVA, V. P. R.; SOUSA, F. A. S. Programa computacional para estimativa da temperatura do ar para a Região Nordeste do Brasil. Revista Brasileira de Engenharia Agrícola e Ambiental, v.10, p.140-147, 2006.

CECÍlLIO, R. A. et al. Método para a espacialização dos elementos do balanço hídrico climatológico. Pesquisa Agropecuária Brasileira, Brasília, v. 47, n. 4, p. 478-488, 2012.

CONSELHO NACIONAL DO MEIO AMBIENTE. Resolução n. 303, de 20 de mar de 2002. Dispõe sobre parâmetros, definiçõos e limites de áreas de preservação permanente. Disponível em: <http://www.mma.gov.br/conama/>. Acesso em: 10 ago. 2012.

GARCIA, G. J. et al. O uso de geotecnologias no planejamento ambiental. O plano diretor municipal de Tambaú - SP. Engenharia Agrícola, Jaboticabal, v. 30, n. 6, p. 11781190, 2010.

MEDEIROS, S. S. et al. Estimativa e espacialização das temperaturas do ar mínimas, médias e máximas na região Nordeste do Brasil. Revista Brasileira de Engenharia Agrícola e Ambiental, Campina Grande, v.9, n.2, p. 247-255, 2005.

MINISTÉRIO DA AGRICULTURA, PECUÁRIA E ABASTECIMENTO. Zoneamento Agrícola: Portarias segmentadas por UF. Disponível em: $<$ http://www.agricultura.gov.br/politicaagricola/zoneamento-agricola/portariassegmentadas-por-uf $>$. Acesso em: 03 nov. 2012.

NASCIMENTO, M. C. et al. Uso do geoprocessamento na identificação de conflito de uso da terra em áreas de preservação permanente na bacia hidrográfica do rio Alegre, Espirito Santo. Ciência Florestal, Santa Maria, v. 15, n. 2, p. 207-220, 2005.

OLIVEIRA, F. S. et al. Identificação de conflito de uso da terra em áreas de preservação permanente no entorno do parque nacional do Caparaó, estado de Minas Gerais. Revista Árvore, Viçosa, v. 32, n. 5, p. 899908, 2008.

PEREIRA, A. R.; ANGELOCCI, L. R.; SENTELHAS, P. C. Meteorologia Agrícola. Departamento de Ciências Exatas, p. 173, Piracicaba, SP, 2007. 
PELUZIO, T. M. O.; SANTOS, A. R.; FIELDER, N. C. Mapeamento de áreas de preservação permanente no ArcGIS 9.3. Alegre - ES: CAUFES, 2010. 58p.

RODY, Y. P. et al. Delimitação de sítios ambientais homogêneos no Estado do Espírito Santo, com base no relevo, solo e clima. Ciência Rural, Santa Maria, v. 40, n. 12, p. 2493-2498, 2010.

SOARES, V. P. et al. Mapeamento de áreas de preservação permanentes e identificação dos conflitos legais de uso da terra na bacia hidrográfica do ribeirão são Bartolomeu - MG. Revista Árvore, Viçosa, v. 35, n. 3, p.
$555-563,2011$.

SREEDEVI, P. D. et al. Morphometric analysis of a watershed of South India using SRTM data and GIS. Journal Geological Society of India, v. 73, n. 4, p. 543-552, 2009.

THORNTHWAITE, C. W. An approach toward a rational classification of climate. Geographical Review, v. 38, n. 1, p. 55-94, 1948.

THORNTHWAITE, C. W.; MATHER, J.R. The Water Balance. Centexton: Laboratory of Climatology, 1955. 104p. (Publications in Climatology, 2). 